\title{
Light Curing Portable dengan 3 Mode Penyinaran
}

\author{
(Stepped, Ramped, Dan Pulse-Delayed)
}

\author{
Riska Dwi Rahma Anggaraini, Endang Dian Setioningsih, Abd. Kholiq, Liliek Soetjiatie \\ Jurusan Teknik Elektromedik Poltekkes Kemenkes Surabaya \\ Jl. Pucang Jajar Timur No. 10, Surabaya, 60245, Indonesia \\ riskadranggaraini@gmail.com,diancholik@gmail.com, abd22@poltekkesdepkes-sby.ac.id
}

\begin{abstract}
Abstrak - Light curing merupakan alat kedokteran gigi yang menghasilkan cahaya tampak dengan panjang gelombang 400-500 nm. Light Curing sendiri digunakan untuk mengeraskan bahan tambal gigi. Penambalan pada gigi tersebut dilakukan karena terjadinya kerusakan pada struktur gigi (karies). Salah satu bahan tambal gigi untuk mengganti struktur gigi yang hilang yang digunakan saat ini adalah resin komposit. Alat ini akan menyinari resin komposit dengan waktu yang telah ditentukan, Penulis menggunakan Arduino NANO sebagai pengatur waktu pada alat. Proses penyinaram pada alat ini dilengkapi dengan 3 Mode Penyinaran (Stepped, Ramped, Dan Pulse-Delayed) dan juga pengaturan intensitas cahaya untuk mode konvensional. Berdasarkan hasil pengujian dan pengambilan data dengan mengukur kekerasan resin komposit dengan alat Hardness Tester, resin komposit yang di berikan penyinaran dengan waktu 20 detik, 40 detik dan 60 detik dengan ketebalan resin komposit $2 \mathrm{~mm}$. Pada alat dengan tambahan 3 mode dan tambahan pemilihan intensitas penyinaran dengan waktu 20 detik belum dapat memenuhi, namun pada penyinaran dengan waktu 40, dan 60 detik sudah dapat memenuhi tingkat kekuatan kunyah manusia yang mampu menahan sebesar 47 Ba. Pada hasil penyinaran 20 detik belum dapat memenuhi, hal ini dapat dipengaruhi oleh beberapa faktor diantaranya spesifikasi LED yang digunakan berbeda, kondisi lingkungan saat pemberian penyinaran pada resin komposit, kurangnya ketelitian saat menyiapkan sample yaitu kurang ratanya permukaan sample, dan ketelitian pembacaan saat pengujian.
\end{abstract}

Kata Kunci-Light Cure, Stepped, Ramped, Pulse-Delayed, Keries, Resin Komposit, LED

\section{LATAR BELAKANG}

Light Curing merupakan alat kedokteran gigi yang menghasilkan cahaya tampak dengan panjang gelombang 400$500 \mathrm{~nm}$. Sinar biru dari alat light cure dihasilkan dari lampu yang difilter dan didistribusikan ke ujung light cure menggunakan bahan fiber optik untuk mengahsilkan sinar dengan panjang gelombang 400-500nm. Light Curing sendiri digunakan untuk mengeraskan bahan tambal gigi.

Penambalan pada gigi tersebut dilakukan karena terjadinya kerusakan pada struktur gigi (Karies). Karies adalah suatu penyakit infeksi yang dihasilkan dari interaksi bakteri. Karies gigi terjadi karena proses demineralisasi dari interaksi bakteri pada permukaan gigi. Bakteri bersifat asam sehingga dalam periode waktu tertentu, asam akan merusak email gigi dan menyebabkan gigi menjadi berlubang. Faktor etiologi terjadinya karies yaitu mikroorganisme plak, diet dan waktu [1]. Dan upaya penanggulangan karies agar tidak meluas adalah melakukan penambalan pada gigi untuk mengembalikan fungsi rongga mulut yang terganggu akibat hilangnya harmonisasi oklusal dan kehilangan gigi geligi, karena penyakit karies sendiri bersifat progresif dan kumulatif [2].

Salah satu bahan tambal gigi untuk mengganti struktur gigi yang hilang yang digunakan saat ini adalah resin komposit sinar tampak yang dipolimerisasi oleh cahaya dengan panjang gelombang tertentu [3]. Hal ini dikarenakan dengan adanya bantuan Light Curing, resin komposit dapat berpolimerisasi dengan baik hingga ketebalan $2 \mathrm{~mm}$ dengan waktu penyinaran 60 detik dan panjang gelombang 460-485nm [4]. Empat jenis sumber polimerisasi telah dikembangkan dan diterapkan: quartz tungsten halogen (QTH) kuarsa, light emitting diodes (LED), lampu plasma-arc dan laser argon-ion [5].

Sehubungan dengan itu, pembuatan light curing ini merujuk pada penelitian sebelumnya yang telah dibuat oleh Agustinus Dwi Prastowo pada tahun 2012 dengan judul "Modifikasi Light Cure Litex 680 A Dilengkapi Tampilan LCD dengan Menggunakan Micrcontroller ATTiny". Hasil pemodifikasian ini masih menggunakan light curing yang menggunakan quartz tungsten halogen (QTH). Sumber cahaya QTH berasal dari bohlam $75 \mathrm{~W}$ yang mana memiliki banyak kekurangan jika digunakan untuk melakukan proses penyinaran bahan tambal gigi, Efisiensi mereka dalam mengubah energi elektronik menjadi cahaya diperkirakan rendah. Hingga $70 \%$ diubah menjadi panas dan hanya $10 \%$ terlihat cahaya, termasuk kisaran biru yang diinginkan untuk polimerisasi. Oleh karena itu, filter diperlukan untuk mengurangi energi panas yang ditransfer. Dari cahaya tampak, karena penggunaan filter cutoff, $90 \%$ selanjutnya terbuang sia-sia. Oleh karena itu, output lampu biru akhir kurang dari 1\% dari total input energi. Selain itu, filter cahaya menurun seiring waktu karena suhu operasi yang tinggi dan kedekatannya dengan bola lampu halogen. Beberapa penelitian telah menunjukkan bahwa banyak unit halogen yang digunakan oleh dokter tidak mencapai output daya minimum yang ditentukan oleh pabrikan [5]. Hasil pemodifikasian ini juga hanya memiliki satu mode penyinaran yaitu mode konvensional. 
Berdasarkan hasil identifikasi masalah pada hasil penelitian sebelumnya didapatkan hasil bahwa dengan kondisi tersebut, maka penulis akan mencoba mengatasi dengan kelemahan yang ada pada alat sebelumnya dan memanfaatkan peluang serta meminimalisir ancaman dengan mengganti lampu quartz tungsten halogen dengan light emiting diode (LED) dengan penambahan tiga mode penyinaran dan pengaturan intensitas cahaya untuk mode konvensional dan merancangnya menjadi "Light Curing Portable Dengan Penambahan 3 Mode Penyinaran (Stepped, Ramped, dan Pulse-Delayed)".

\section{BAHAN DAN METODE}

\section{A. Desain Penelitian}

Rancangan penelitian model alat ini menggunakan metode Pre-eksperimental dengan jenis penelitian One Group Post Test Design. Dimana penulis melakukan pengambilan sample resin komposit yang telah di berikan penyinaran. Kemudian melakukan pengujian performa alat dan juga melakukan pembandingan antara alat yang dibuat dengan alat standar.

\section{1) Alat dan Bahan}

Penelitian ini menggunakan alat berupa toolkit dan avo meter dalam melakukan perancangannya. Dan bahan - bahan yang digunakan dalam perancangan alat ini, diantaranya adalah LED Bridgelux sebagai sumber cahaya. Arduino Nano sebagai pengolah data PWM dan LCD Oled sebagai displaynya, selain itu untuk sumber daya alat ini menggunakan baterai.

\section{2) Percobaan}

Pada penelitian ini peneliti melakukan pengukuran dengan alat Hardness Tester, resin komposit di berikan penyinaran dengan menggunakan 3 mode yang berbeda yaitu mode stepped, ramped dan pulse-delay dengan waktu 20 detik, 40 detik dan 60 detik dengan ketebalan resin komposit $2 \mathrm{~mm}$.

\section{B. Blok Diagram}

Batterai sebagai sumber tegangan. Ketika power di keadaan ON maka indikator batterai menyala, bersamaan dengan LCD. Tombol $U p$ digunakan untuk melakukan pemilihan agar kursor bergerak keatas, tombol Down berfungsi untuk melakukan pemilihan agar kursor bergerak kebawah, tombol Next digunakan ketika pengguna ingin melanjutkan ke pengaturan selanjutnya, dalam melakukan pemilihan jika sudah selesai melakukan pengaturan waktu maka dapat menekan tombol Next untuk melanjutkan pemilihan mode penyinaran dan selanjutnya. Sedangkan tombol Start berfungsi untuk memulai proses penyinaran setelah melakukan pengaturan waktu, mode dan intensitas. Pada saat pengguna menekan tombol Start maka akan memberikan input kepada Arduino Nano agar memproses dan memberikan perintah untuk bekerja. Dengan berkerjanya maka akan mengaktifkan lampu LED. LCD akan menampilkan pemilihan waktu, mode, dan intensitas yang akan digunakan untuk penyinaran tambal gigi. Pada saat penyinaran telah tercapai sesuai pengaturan, maka Arduino nano akan menginteruksi untuk berhenti bekerja yang ditandai dengan matinya lampu LED.

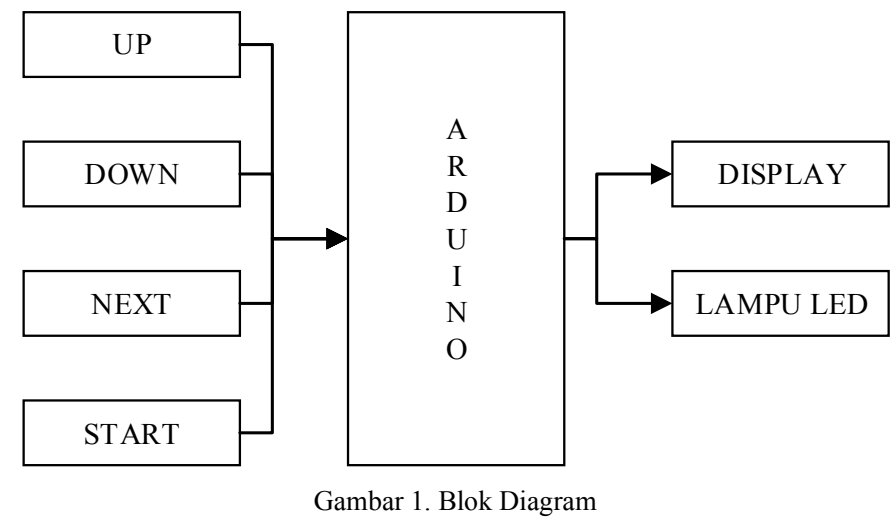

\section{Diagram Alir}

Begin untuk memulai proses alat light cure, LCD akan melakukan inisialisasi. Sebelumnya atur waktu, mode dan intensitas untuk melakukan penyinaran, setelah pengaturan alat maka tekan tombol start maka LED akan menyala sesuai dengan pengaturan yang telah diatur sebelumnya. Setelah waktu tercapai, lampu akan off. End menandakan telah berakhirnya proses penyinaran.

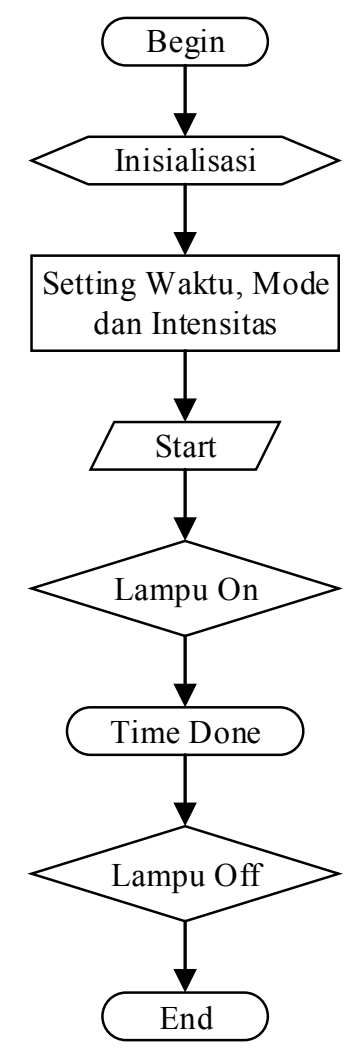

Gambar 2. Diagram Alir Proses 
D. Rangkaian Regulator

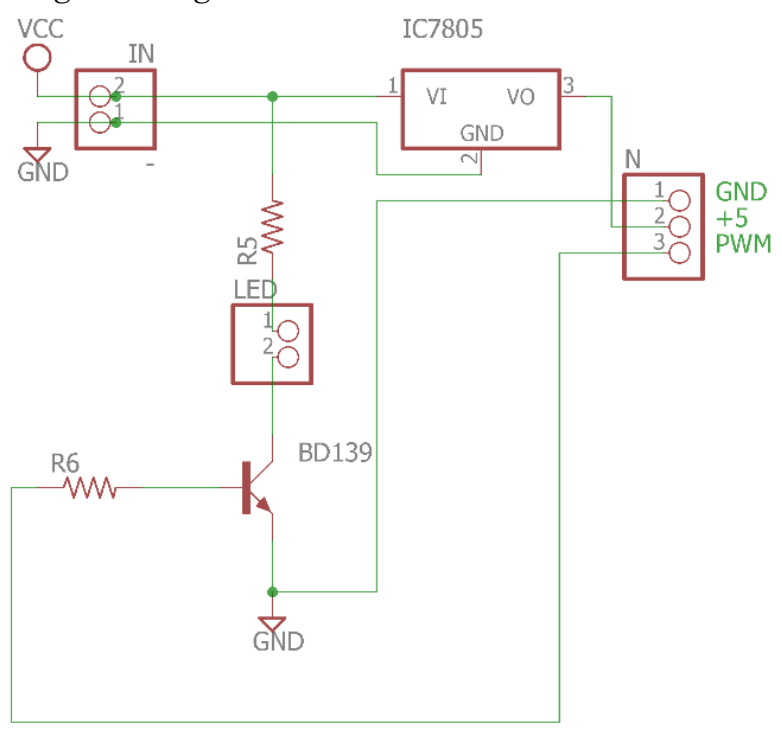

Gambar 3. Rangkaian Catu Daya

Pada gambar 3 merupakan rangkaian regulator, Input dari rangkaian regulator berasal dari Baterai yang kemudian masuk pada IC7805 sebagai IC regulator yang akan mengeluarkan Output +5 Volt sebagai Supply untuk rangkaian Arduino Microcontroller. Sedangkan untuk LED, akan menyala apabila transistor NPN BD139 saturasi setelah mendapat peritah dari PWM.

\section{E. Rangkaian Arduino Microcontroller}

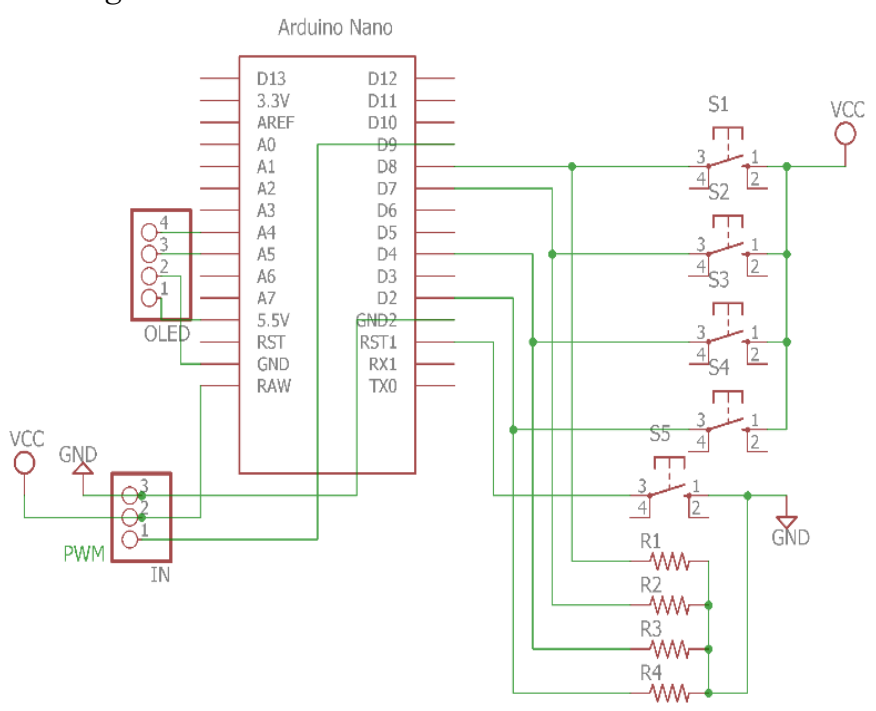

Gambar 4. Rangkaian Arduino Microcontroller

Pada gambar 4 merupakan rangkaian Arduino Microcontroller, Output +5 Volt dari rangkaian regulator masuk ke Rangkaian Arduino Microcontroller. Rangkaian Arduino Microcontroller berfungsi untuk mengatur lama waktu penyinaran, mode dan intensitas penyinaran LED dengan Input dari Push Button dan ditampilkan pada LCD Oled.
III. HASIL

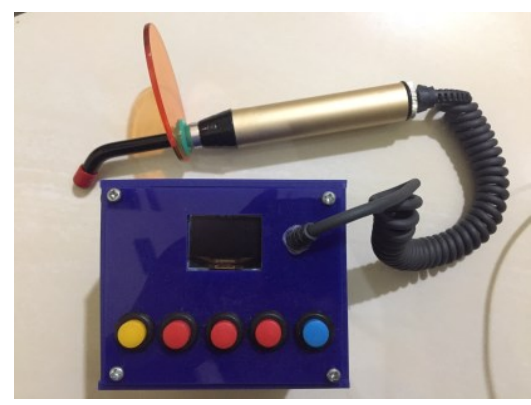

Gambar 5. Hasil Modul Tampak Atas

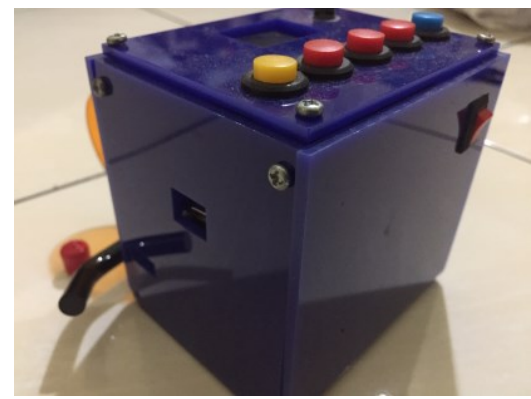

Gambar 6. Hasil Modul Tampak Samping
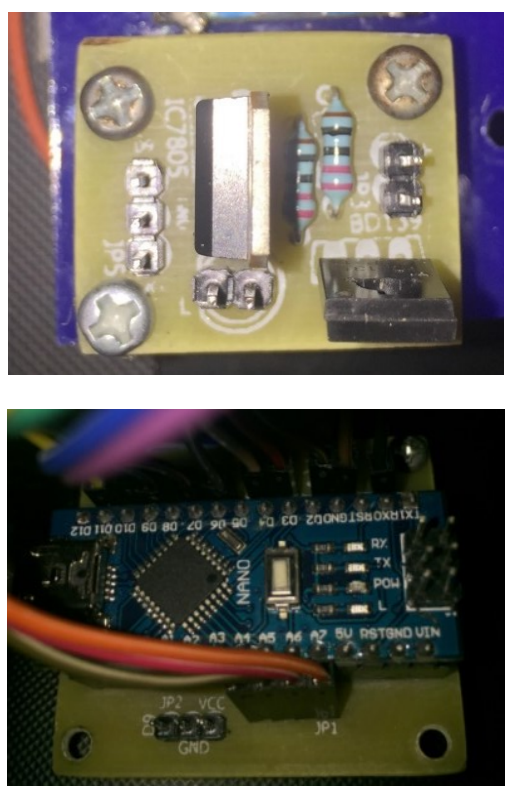

Gambar 7. Rangkaian Regulator dan Rangkaian Arduino Microcontroller

\section{1) Desain Modul}

Pada Gambar 5 dan Gambar 6 merupakan hasil desain modul yang terlihat dari atas dan dari samping. Untuk konektor dari rangkaian ke LED terletak pada modul bagian atas. Di dalam modul terdapat Rangkaian Catu Daya yang outputnya disambungkan dengan Rangkaian Arduino Microcontroller.

\section{2) Listing Program}

Listing program 1. Program Inisialisasi 


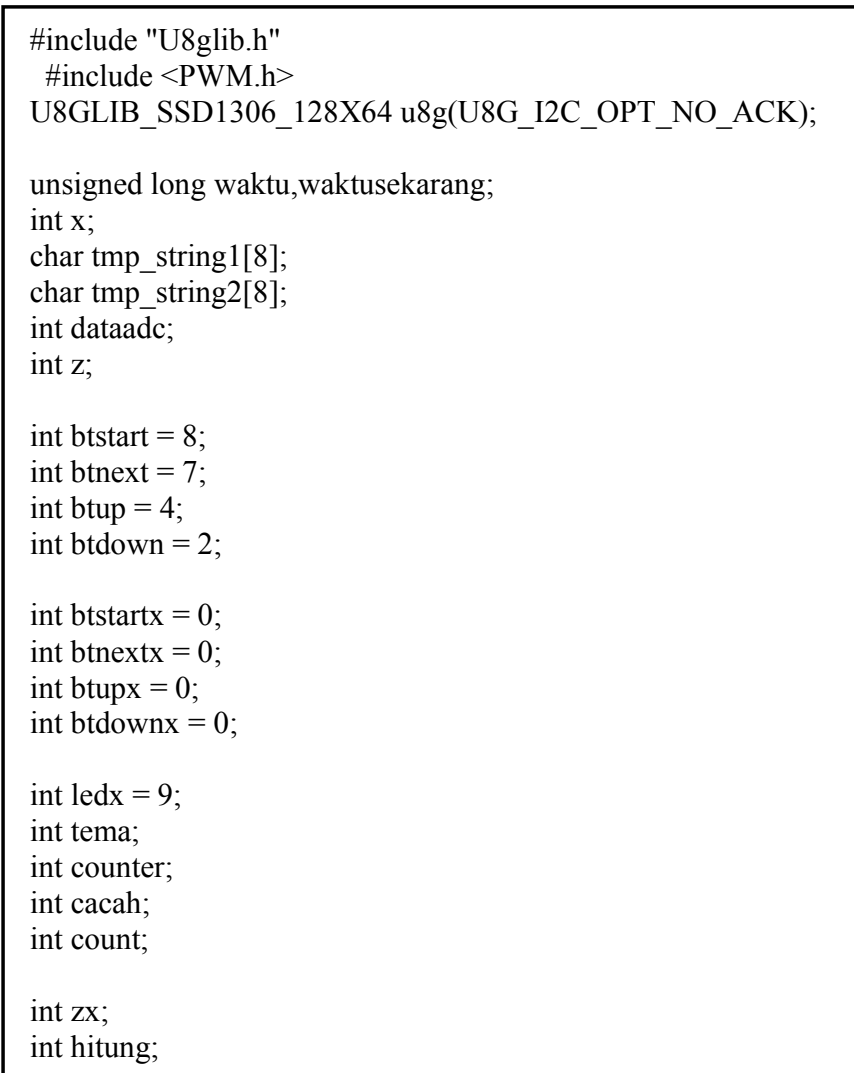

Program diatas adalah untuk memasukkan library LCD OLED dan PWM agar terhubung dengan Arduino. Pada program ini menggunakan timer dengan inisialisasi "unsigned long waktu,waktusekarang".

Listing Program 2. Program Setup

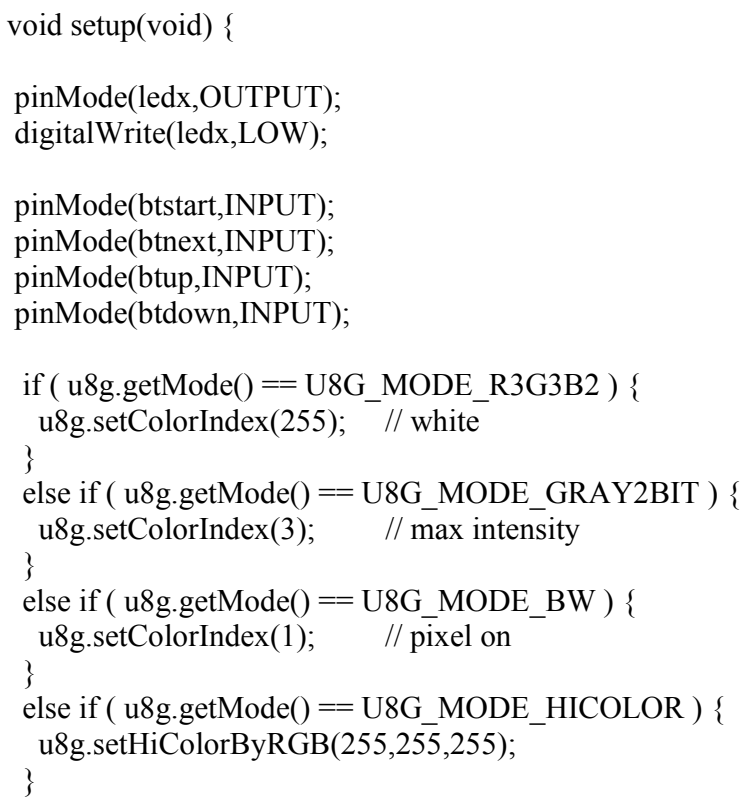

Program diatas difungsikan untuk mengatur pin arduino yang akan menjadi input dan output dari push button dan PWM serta mengatur tampilan Oled dari Arduino.

Listing Program 3. Program Pengaturan Penyinaran Led

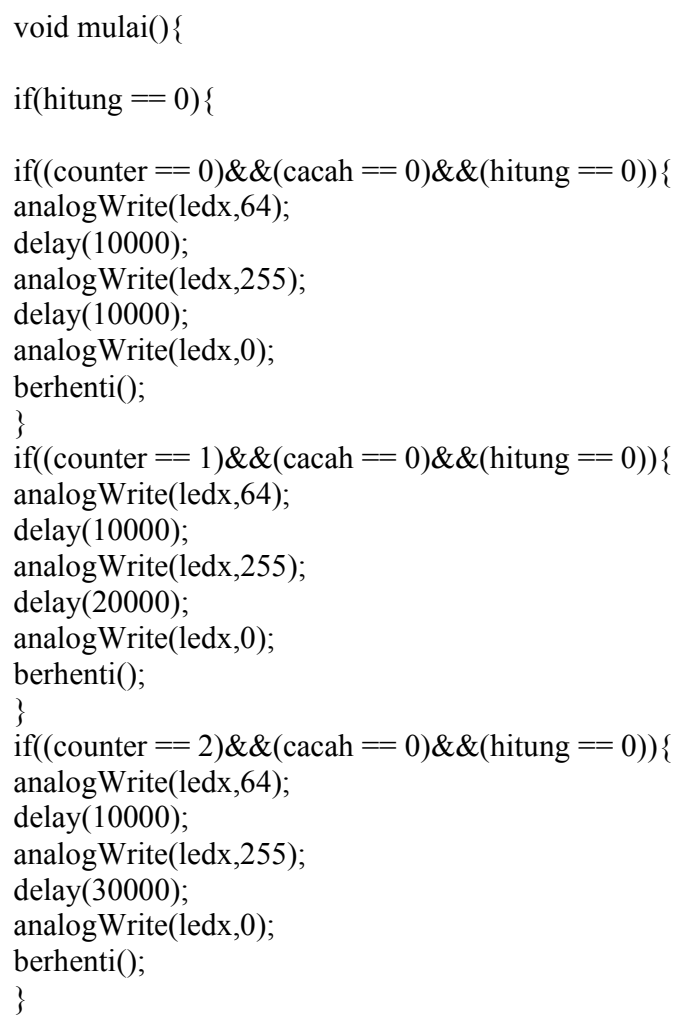




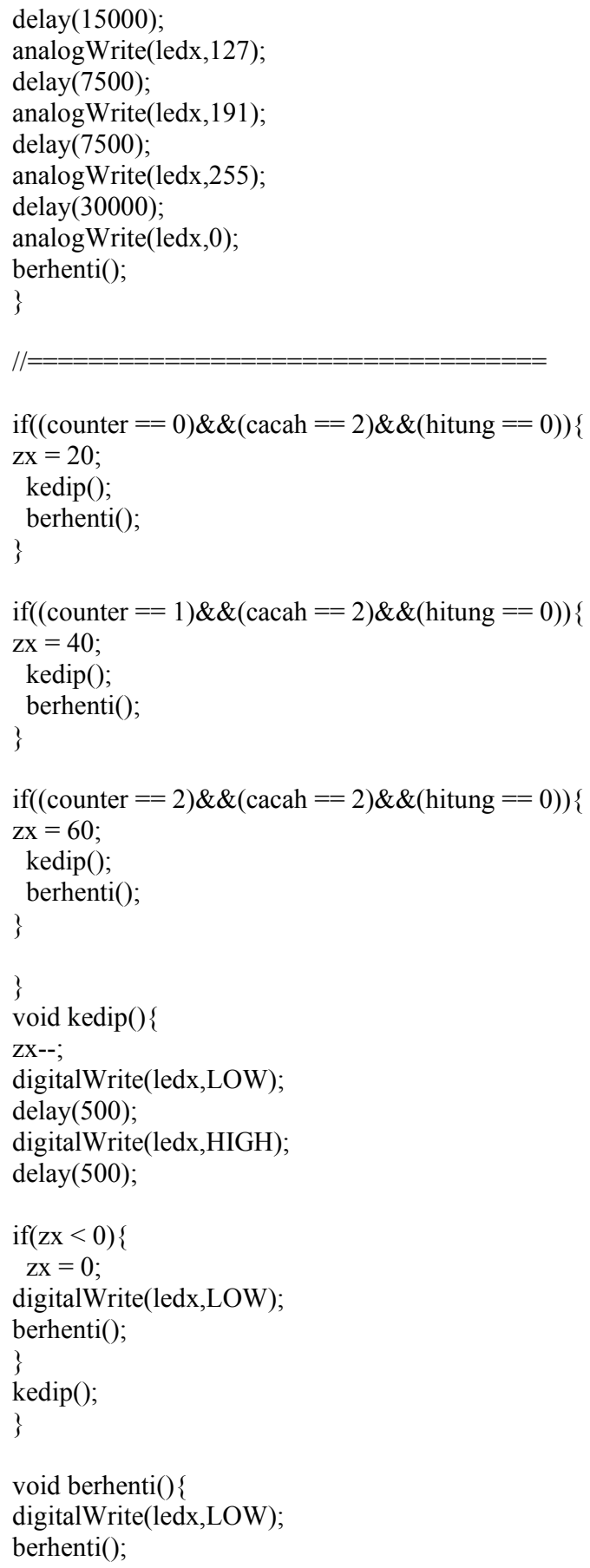

Program diatas adalah untuk mengatur waktu atau timing penyinaran LED dengan pengaturan delay menjadi 20 detik, 40 detik dan 60 detik. Dan untuk mengatur mode penyinaran dengan mode 1 yaitu Redup dan Terang mode 2 yaitu Redup, Sedang, Terang serta mode 3 yaitu Berkedip (Mati-Hidup) dengan pembagian waktu timing setiap perubahan mode dari penyinaran LED.

3) Analisis Data Pengukuran
TABEL I. HASIL PEMBANDINGAN MODUL DENGAN STANDARD

\begin{tabular}{|c|c|c|c|c|c|c|}
\hline \multicolumn{7}{|c|}{ Hasil Pengukuran ( Ba ) } \\
\hline \multicolumn{7}{|c|}{ Penyinaran 20 detik } \\
\hline $\begin{array}{c}\text { Data } \\
\text { ke- }\end{array}$ & $\begin{array}{c}\text { Mode } \\
1\end{array}$ & $\begin{array}{c}\text { Mode } \\
2\end{array}$ & $\begin{array}{c}\text { Mode } \\
3\end{array}$ & $\begin{array}{c}\text { Intensitas } \\
\text { Terang }\end{array}$ & $\begin{array}{c}\text { Intensitas } \\
\text { Redup }\end{array}$ & $\begin{array}{l}\text { Alat } \\
\text { Asli }\end{array}$ \\
\hline 1 & 40 & 40,5 & 40,5 & 44 & 40 & 48 \\
\hline 2 & 41 & 40 & 40 & 45,5 & 41 & 47 \\
\hline 3 & 40 & 41 & 40 & 45 & 41 & 47,5 \\
\hline 4 & 41,5 & 41 & 40 & 46,5 & 40,5 & 48 \\
\hline 5 & 41 & 42,5 & 40,5 & 46 & 41 & 47 \\
\hline 6 & 41 & 41 & 40 & 46 & 40,5 & 47 \\
\hline \multicolumn{7}{|c|}{ Penyinaran 40 detik } \\
\hline 1 & 48 & 45 & 44,5 & 51 & 44,5 & 54 \\
\hline 2 & 50 & 46 & 43,5 & 51 & 44 & 53,5 \\
\hline 3 & 48,5 & 46 & 44 & 50 & 44 & 54 \\
\hline 4 & 49 & 46 & 44,5 & 52 & 44,5 & 55 \\
\hline 5 & 48 & 45,5 & 45 & 52,5 & 45 & 54 \\
\hline 6 & 48,5 & 46 & 45,5 & 52,5 & 45 & 54 \\
\hline \multicolumn{7}{|c|}{ Penyinaran 60 detik } \\
\hline 1 & 54 & 51 & 52 & 63 & 54 & 65 \\
\hline 2 & 55 & 51,5 & 53 & 63,5 & 55 & 65,5 \\
\hline 3 & 55 & 51 & 53 & 62 & 54,5 & 65 \\
\hline 4 & 54,5 & 51 & 53 & 63 & 55 & 66 \\
\hline 5 & 54 & 51,5 & 53,5 & 63,5 & 55 & 66 \\
\hline 6 & 55 & 51 & 53 & 62,5 & 55,5 & 65 \\
\hline
\end{tabular}

TABEL II. HASIL PERHITUGAN PADA PENYINARAN 20 DETIK

\begin{tabular}{|c|c|c|c|c|}
\hline \multicolumn{5}{|c|}{ Penyinaran 20 Detik } \\
\hline Hasil Pengukuran & Rata-Rata & Standar Deviasi & $\mathrm{Ua}$ & $\begin{array}{c}\text { Error } \\
(\%)\end{array}$ \\
\hline Mode 1 & 40,8 & 0,6 & 0,3 & \multirow{6}{*}{4,0} \\
\hline Mode 2 & 41,0 & 0,8 & 0,3 & \\
\hline Mode 3 & 40,2 & 0,3 & 0,1 & \\
\hline Intensitas Terang & 45,5 & 0,9 & 0,4 & \\
\hline Intensitas Redup & 40,7 & 0,4 & 0,2 & \\
\hline Alat Asli & 47,4 & 0,5 & 0,2 & \\
\hline
\end{tabular}

TABEL III. HASIL PERHITUGAN PADA PENYINARAN 40 DETIK

\begin{tabular}{ccccc}
\hline \multicolumn{4}{c}{ Penyinaran 40 Detik } & \\
\hline Hasil Pengukuran & Rata-Rata & Standar Deviasi & Ua & $\begin{array}{c}\text { Error } \\
(\%)\end{array}$ \\
\hline Mode 1 & 48,7 & 0,8 & 0,3 & 4,8 \\
\hline
\end{tabular}




\begin{tabular}{cccc}
\hline Mode 2 & 45,8 & 0,4 & 0,2 \\
\hline Mode 3 & 44,5 & 0,7 & 0,3 \\
\hline Intensitas Terang & 51,5 & 1,0 & 0,4 \\
\hline Intensitas Redup & 44,5 & 0,4 & 0,2 \\
\hline Alat Asli & 54,1 & 0,5 & 0,2 \\
\hline
\end{tabular}

TABEL IV. HASIL PERHITUGAN PADA PENYINARAN 60 DETIK

\begin{tabular}{|c|c|c|c|c|}
\hline \multicolumn{5}{|c|}{ Penyinaran 60 Detik } \\
\hline Hasil Pengukuran & Rata-Rata & Standar Deviasi & $\mathrm{Ua}$ & $\begin{array}{c}\text { Error } \\
(\%)\end{array}$ \\
\hline Mode 1 & 54,6 & 0,5 & 0,2 & \multirow{6}{*}{3,8} \\
\hline Mode 2 & 51,2 & 0,3 & 0,1 & \\
\hline Mode 3 & 52,9 & 0,5 & 0,2 & \\
\hline Intensitas Terang & 62,9 & 0,6 & 0,2 & \\
\hline Intensitas Redup & 54,8 & 0,5 & 0,2 & \\
\hline Alat Asli & 65,4 & 0,5 & 0,2 & \\
\hline
\end{tabular}

Dari hasil analisis tingkat kekerasan resin komposit yang dilakukan dengan membandingkan hasil pengujian tingkat kekerasan sampel yang disinari light cure yang di berikan tambahan 3 mode dan tambahan pilihan intesitas dengan light cure asli, hasil rata-rata pengujian kekerasan pada sampel yang disinari light cure yang di berikan tambahan 3 mode dan tambahan pilihan intesitas dengan waktu 20 detik diketahui pada Mode 1 didapatkan nilai rata 40,8 $\mathrm{Ba}$, Mode 2 didapatkan nilai rata 41,0 $\mathrm{Ba}$, Mode 3 didapatkan rata nilai 40,2 $\mathrm{Ba}$, Intensitas $\mathrm{T}$ didapatkan nilai rata $45,5 \mathrm{Ba}$, dan Intensitas $\mathrm{R}$ didapatkan nilai rata $40,7 \mathrm{Ba}$. Pada sampel yang disinari dengan waktu 40 detik diketahui pada Mode 1 didapatkan nilai rata 48,7 $\mathrm{Ba}$, Mode 2 didapatkan nilai rata 45,8 $\mathrm{Ba}$, Mode 3 didapatkan rata nilai $44,5 \mathrm{Ba}$, Intensitas $\mathrm{T}$ didapatkan nilai rata 51,5 Ba, dan Intensitas $\mathrm{R}$ didapatkan nilai rata 44,5 Ba. Pada sampel yang disinari dengan waktu dan 60 detik diketahui pada Mode 1 didapatkan nilai rata 54,6 Ba, Mode 2 didapatkan nilai rata 51,2 $\mathrm{Ba}$, Mode 3 didapatkan rata nilai 52,9 $\mathrm{Ba}$, Intensitas $\mathrm{T}$ didapatkan nilai rata $62,9 \mathrm{Ba}$, dan Intensitas $\mathrm{R}$ didapatkan nilai rata $54,8 \mathrm{Ba}$. Dan hasil rata-rata pengujian kekerasan pada sampel yang disinari light cure asli dengan waktu 20 detik didapatkan nilai rata $47,4 \mathrm{Ba}$, dengan waktu 40 detik didapatkan nilai rata $54,1 \mathrm{Ba}$, dengan waktu 60 detik didapatkan nilai rata $65,4 \mathrm{Ba}$. Hasil dari rata rata nilai yang yang didapatkan menunjukkan nilai kekerasan yang berbeda, Nilai diatas jika dibandingkan dengan nilai yang diketahui bahwa tingkat kekuatan kunyah manusia yang mampu menahan sebesar $314 \mathrm{Mpa}$ [6]. Yang apabila di konversi pada pada satuan $\mathrm{Ba}$ yaitu $47 \mathrm{Ba}$ [7], yang berarti pada alat asli hasil dari penyinaran dengan waktu 20, 40 dan 60 sudah dapat memenuhi, namun pada alat dengan tambahan 3 mode dan tambahan pemilihan intensitas pada penyinaran dengan waktu 20 detik belum dapat memenuhi namun pada penyinaran dengan waktu 40, dan 60 detik sudah dapat memenuhi.

\section{KESIMPULAN}

Rangkaian Arduino Nano dapat digunakan untuk mengontrol system mode penyinaran, waktu penyinaran dan intensitaas penyinaran. Light Cure dapat menggunakan Led jenis Hpl (high power led) untuk menggantikan lampu halogen sebagai sumber cahaya. Setelah dilakukan pengujian alat dapat dibuktikan bahwa alat ini dapat berkerja untuk mengeraskan resin komposit. Pada alat dengan tambahan 3 mode dan tambahan pemilihan intensitas penyinaran dengan penyinaran waktu 40 dan 60 detik sudah dapat memenuhi. Beberapa faktor yang mempengaruhi kekerasan resin komposit diantaranya spesifikasi LED yang digunakan, kondisi lingkungan saat pemberian penyinaran, kurangnya ketelitian saat menyiapkan sample dan ketelian pembacaan saat pengujian.

Menggunakan Led 5 Watt karena yang penulis gunakan adalah Led 3 Watt yang mana masih kurang cerah, sehingga tidak dapat memberikan cahaya yang sempurna untuk membantu proses pengerasan resin komposit. Memerhatikan kondisi lingkungan dan membuat cetakan resin yang memiliki permukaan rata sehingga resin yang dihasilkan mudah untuk diukur kekerasannya menggunakan alat ukur.

\section{DAFTAR PUSTAKA}

[1] M. D. Mustika, A. N. Carabelly, And Cholil, "Insidensi Karies Gigi Pada Anak Usia Prasekolah Di Tk Merah Mandiangin Martapura Periode 2012-2013," Dentino J. Kedokt. Gigi, Vol. Ii, No. 2, Pp. 180 $184,2014$.

[2] E. Y. Heta, Rosihan Adhani, "Hubungan Tingkat Pengetahuan, Ketersediaan Fasilitas, Dan Dorongan Petugas Kesehatan Terhadap Tindakan Masyarakat Untuk Menambal Gigi,” J. Kedokt. Gigi, Vol. I, No. 1, P. 56, 2014.

[3] Y. Pasril And W. A. Pratama, "Perbandingan Kekuatan Tekan Resin Komposit Hybrid Menggunakan Sinar Halogen Dan Led Comparison Of Compressive Strength Hybrid Composite Resin Using Halogen And Led Light," Idj, Vol. 2, No. 2, Pp. 83-90, 2013.

[4] J. Allorerung, P. S. Anindita, And P. N. Gunawan, "Uji Kekerasan Resin Komposit Aktivasi Sinar Dengan Berbagai Jarak Penyinaran," J. E-Gigi, Vol. 3, Pp. 0-4, 2015.

[5] L. Ceballos Et Al., "Curing Effectiveness Of Resin Composites At Different Exposure Times Using Led And Halogen Units," Vol. 14, No. 1, Pp. 1-6, 2009.

[6] Z. H. Ilyas, "Rancang Bangun Light Cure Menggunakan Microcontroller Atmega8 Program Studi D3 Teknik Elektromedik Program Vokasi Universitas Muhammadiyah Yogyakarta," 2017.

[7] T. John And H. P. H. Conrad, "The Impressor," Vol 10, No.2 October, 2002 . 